\title{
INCONSISTENCY, UNCERTAINTY AND EPISTEMIC AUTHORITY
}

\section{DAMIAN LESZCZYŃSKI}

University of Wrocław

The book of Linda Zagzebski deals with the serious and complex problem of epistemic authority - a problem concerning not only epistemology, but also some topics in practical philosophy: ethics and political philosophy. It is hard to refer to all of the issues brought up in the book, so I will try so to concentrate on those which, in my opinion, are most essential and involve the problem of self-reliance. This issue is essential and its correct analysis is a condition of the possibility of conducting further argumentation. I do not intend to summarize all solutions presented in the book; I am only going to refer to those aspects of Zagzebski's argumentation which are, in my opinion, problematic and doubtful: the problem of dissonance and its elimination as rational purpose; the problem of 'naturalness', the reconstruction of epistemic authority and, finally, the interpretation of Descartes' philosophy.

I.

Zagzebski's statement that our thinking consists in, generally speaking, the elimination of dissonance (that is the incompatibility or conflict between our acts or mental states), is similar to the well-known conception of Charles S. Peirce which was introduced in the article How to Make Our Ideas Clear. However, it means that analyses have a rather psychological character and not epistemological (in Peirce's philosophy, similarly as in the philosophy of Dewey, epistemology was in fact replaced by cognitive psychology). But in this way we are going from the level of questio iuris to the level of questio facti, losing the normative dimension of our investigations which seem essential when we try to 
solve problems concerning morality (discussed in chapter 8 ). It seems that we should first consider what in fact is a priority for us: harmonious views (psychological optimum) or whether they are true (epistemological optimum)? It is an important issue because these things are not necessarily connected with each other. It is not that when we achieve harmony and coherence (as a result of the elimination of dissonance) we automatically achieve the truth. It can simply be the other way round. It is often the case that we achieve harmony at the cost of the truth, for example in various forms of ideology or pseudoscience (e.g. David Icke's theory of reptilian humanoids is perfectly cohesive, but it seems at the same time totally false). ${ }^{1}$ I would even say that the excellent cohesion of certain systems of statements or opinions should arouse our suspicion: e.g. some schizophrenics' systems of beliefs are truly harmonious and their verification from the point of truth must lead to the introduction of a deep dissonance. Also in the history of science we have numerous examples of the introduction within existing conceptual schemes of some hypotheses ad hoc in order to provide them with harmony (e.g. attempts to rescue Newton's mechanics in the late $19^{\text {th }}$ century). However, it did not increase the cognitive power of these schemes and ultimately did not inspire greater confidence.

II.

I have great doubts concerning whether aiming to remove dissonance can be regarded en bloc as a rational action. Nowadays a similar position is taken by Jurgen Habermas, who proposed a theory of communicative actions as a general theory of the equalization of dissonances. His idea of a harmonized communication based on a global consensus, is presented as an a priori rational purpose. However, as presented by, among others, Nicholas Rescher in his book Pluralism: Against the Demand for Consensus, this assumption is highly controversial. Rescher's view is exactly contrary to Habermas's - both in ourselves, as well as within a community, a conflict, a dispute and dissonance are rational because they have a stimulating effect. Moreover, from the point of

\footnotetext{
${ }^{1}$ Coherence may be a necessary condition of truth in the case of sets of statements but not in the case of an individual statement. We can imagine a set of incoherent statements which are individually true, for example pragmatically. It is one of the consequences of Gödel's incompleteness theorems. (This, however, is not the place to discuss this problem in detail.)
} 
view of Popperian falsificationism (which in some respects is a reliable description of how a scientific community works) a rational action is the pursuit of dissonance and the introduction of an inconsistency into the system of our beliefs by submitting our hypotheses to extremely restrictive tests. Let us also recall a classical example of Socrates. His method consisted exactly in the demolition of harmony, the introduction of dissonance, and finally providing his audience with no clear answers but with new questions and problems. I would say that this is the core of any philosophical and intellectual activity: posing questions, formulating doubts, introducing dissonance and formulating questions. And the fact that in solving fundamental philosophical problems, in my opinion, no significant progress has been made since the time of Plato, shows that a dissonance is included in the nature of philosophical enquiry and is something which supports it. So it seems that we do not need to eliminate dissonance but we have to maintain it.

III.

In this context it is possible to make some classifications of dissonances and their forms. Zagzebski makes some classification in her book (p. 50) where she mentions some dissonances between beliefs, emotions and actions as well as dissonances between beliefs and desires. I think that these divisions can be more sophisticated and systematic when we consider dissonance or incoherence on the logical or syntactic level (between statements), epistemic (between cognitive acts and their objects, i.e. between what I see and what is), as well as pragmatic (between statements and acts). It is evident that there is a difference between immanent dissonance, taking place inside the subject between his mental states (cognitive, volitional, emotional), and transcendent dissonance between the subject (and his mental states or acts) and the world (that means: objects, persons, acts, cultural values, etc.). Considering different types of dissonances, it is clear that even acknowledging that rational action consists in the elimination of dissonance, it appears there is no one way of this elimination, because a contradiction of my opinions is something different than a conflict between acts and values or acts and opinions. In my opinion different types of dissonance require us to take into account different types of the rationality that would enable us with regards to them. Subsuming everything under one general category of rationality is not a good idea because excessive generality lacks its 
predicate value. One should also consider certain meta-rationality which is responsible for choosing some local rational actions in reference to specific types of dissonance.

IV.

I am doubtful about the idea of the 'normality' and the 'naturalness' used by Zagzebski (e.g. pp. 86, 201-202, 251-254, where 'normal' is tied together with 'harmony'). It is hard to state whether these terms are used normatively or descriptively, and whether they refer to a biological, cultural, or social norm, or are understood psychologically and associated with the internal integrity of the individual. And since Zagzebski closely connects the idea of rationality with ideas of the normal and the natural, we encounter a big problem here, especially that the concept of rationality - as I demonstrated above - is also problematic. In this context an attempt to solve some sceptical problem by referring sceptical doubts to 'what we naturally do' seems fallible (p. 45). It is not only due to the vagueness of this notion, but also because it is not known why the 'naturalness' would be actually regarded as a criterion of approval in case of philosophical scepticism (I will come back to this issue at the very end of this text).

\section{V.}

I have some objections to the very analysis of the phenomenon of epistemic authority. This analysis is based on some thoughts of Joseph Raz (p. 106), concerning political authority and is some kind of extrapolation of his political ideas in the field of cognition. In my opinion it cannot be done easily, because the nature of political authority is connected with action (practice) and so differs from the nature of epistemic authority, associated rather with speculation and theory. The first authority concerns techne, the second episteme (or doxa) (it is possible here to refer to Oakeshott's classical division of practical knowledge, that is ability, and theoretical knowledge - knowledge in the proper sense of the word). So I would disagree with the statement that epistemic authority 'has all of the essential features of practical authority' (p. 139), because these are two completely different kinds of the authorities. Therefore applying Raz's political analyses to the area of epistemology is unfortunate and cannot be beneficial but rather makes the core of the issue obscure. 
I think that clear and formal characteristics of epistemic authority (and authority in general) proposed half a century ago by Joseph Bochenski, would be a good starting point here. ${ }^{2}$ Bochenski wrote that authority is a relation where $p$ is an authority for $q$ in the domain of $D$, when $q$ accepts everything what $p$ is offering him, and what belongs to the domain of $D$. Bochenski precisely studied cases of justified and unjustified use of authority, trying to show that it is possible to describe them from an external point of view (third-person perspective), not only from the point of view of an inner conviction of an individual (because there is often a case when a deep confidence of the individual in the authority is unjustified). Bochenski analyses not only conditions in which somebody can be an epistemic authority for someone, but also general conditions for being an authority for someone in a certain domain. The central question for Bochenski is the distinction between epistemic and deontic authority corresponding to the above discussed distinction into episteme (theoretical knowledge) and doxa (practical knowledge). However, according to my interpretation, the most important is Bochenski's statement that in the domain of practice - that is in morality, politics, the art of war and the like - there is no (and cannot be) epistemic authority. It results from the fact that there is no scientific theoretical knowledge which would enable anyone to become an epistemic authority in moral, political or existential issues. It is possible to be an epistemic authority in a field of science of morality or science of politics - but not in morality itself or politics itself. In these domains there are of course some authorities, but they have a completely different, deontic character. It shows that applying a structure of political (practical) authority to epistemic problems cannot be made. Obviously, the thesis about the non-existence of epistemic authority in the domain of practice can be questioned, for example proponents of ethical intellectualism would surely disagree with it, but regardless of that I think that Bochenski's analysis deserves attention.

VI.

The last matter which I would like to discuss here is connected with a way in which Zagzebski analyses the philosophy of Descartes. Admittedly, in her book we find only brief references to this thinker in the context of the problem of self-reliance. However, I think that it is worthwhile to devote

${ }^{2}$ Joseph Bochenski, Was ist Autorität? (Freiburg: Herder, 1974). 
more attention to him because the problem of the relation of self-reliance and epistemic authority is precisely analyzed in Descartes' writings.

Let us start with a simple issue. Zagzebski is right on one hand when claiming that it is a mistake to interpret either the Cartesian method of doubt or his foundationalism as a justification of self-reliance' (p. 17) (the problem is more complicated and I will refer to it later on). However, on the other hand she is wrong when stating that Descartes' object of trust is 'the use of human power purified by his method' (ibid.). Indeed, Descartes writes in several places in Meditations that everything that we clearly and distinctly understand is true, but this statement is conditional. The method itself is not trustworthy, but needs a completely external guarantee. And this guarantee is divine truthfulness. In First Meditation Descartes analyzes cases of clear and distinct cognition, starting from sensory perception, and finishing on a priori mathematical reasoning, showing that each of these types of cognition can be dubious. Not only senses can deceive me - I can be deranged, I can dream - but it is also possible that God still deceives me (the hypothesis of the deus deceptor) or there is an all powerful demon deceiver who provides me with an entire image of my world and influences my will in such a way that I accept falsehood for the truth, e.g. when I think that $2+3=5$ (the hypothesis of malin genius). Certainly, even if the malin genius exists and deceives me constantly, at least I am sure about my own existence, but nothing more, much less the existences of any external world. Therefore Descartes must prove that God is not a deceiver (although he needs to show first that I am not in the power of the almighty demon). This proof, as is widely known, is made in Third Meditation through the so-called ontological argument (and we know that this argument encounters substantial criticism). Descartes presents additional arguments in Fifth Meditation, where he writes: 'But once I perceived that there is a God, and also understood at the same time that everything else depends on him and that he is not a deceiver, I then concluded that everything that I clearly and distinctly perceive is necessarily true. ${ }^{3}$ So one can see that for Descartes the authority of the method is absolutely relative towards the authority of God and the authority of God is justified when I know that God is not deceiver.

${ }^{3}$ René Descartes, Meditations, Objections, and Replies, Edited and Translated by R. Ariew and D. Cress (Indianapolis/Cambridge: Hackett Publishing Company, Inc., 2006), p. 39. 
Therefore we clearly see that in the context of the philosophy of Descartes we cannot identify 'epistemic self-reliance with epistemic autonomy', as is suggested by Fricker and quoted by Zagzebski (p. 18). The situation is exactly the opposite: I can trust myself only because I am not autonomous - because I am God's creation and as such I am not misled by God.

But what happens in a situation if God is not my creator, if I was created in some other way? This eventuality is almost universally accepted by contemporary naturalized philosophy. Descartes also analyses this problem:

Perhaps there are some who would rather deny so powerful a God, than believe that everything else is uncertain. Let us not oppose them; rather, let us grant that everything said here about God is fictitious. Now they suppose that I came to be what I am either by fate, or by chance, or by a connected chain of events, or by some other way. But because deceived and being mistaken appear to be a certain imperfection, the less powerful they take the author of my origin to be, the more probable it will be that I am so imperfect that I am always deceived. I have nothing to say in response to these arguments. But eventually I am forced to admit that there is nothing among the things I once believed to be true which it is not permissible to doubt - and not out of frivolity or lack of forethought, but for valid and considered arguments. Thus I must be no less careful to withhold assent henceforth even from these beliefs than I would from those that are patently false, if I wish to find anything certain. ${ }^{4}$

So here we have a clearly posed problem: if I am not created by a good God, if I am not cognitively heteronomous on the epistemic level (e.g. if the basis of my cognition is not dependent on God), I cannot have certain knowledge and I can never trust myself (I cannot believe even in the above statement). If I am a contingent creation of nature, it is possible that I am able to know something truly, but I am not able to verify it - I cannot know that I know something (in other words: even if I accidentally find the truth, I cannot know the criterion to distinguish truth from falsehood). But there is also a possibility that I was created by the evil demon deceiver, and it means that I will never find the truth. But of course this statement is self-referential and can also be false. In this case we finally reach a paradox.

\footnotetext{
${ }^{4}$ Ibid., pp. 11-12.
} 
However, Descartes' solution to the problem of self-reliance is more complex. He writes that we cannot trust ourselves and our knowledge because our senses and our own minds can deceive us. But at the same time Descartes seems to trust himself when he states that senses can deceive him and the mind can be wrong. Therefore here we are faced with two levels on which the issue of the self-reliance is being considered: empirical and transcendental. The first deals with what is called objective knowledge, the act of cognition in which the mind is directed towards transcendent objects (or objects that are recognized as transcendent). Here I should not trust myself, because senses can deceive me, the mind can draw wrong conclusions, etc. But the second level deals with a type of meta-knowledge, meta-cognition where the mind is directed towards itself as the subject who gets to know an object. The discourse of Meditations is conducted at this very level: the subject (ego) has become an object of examination. And in this case Descartes seems to trust himself: when he is formulating sceptical arguments from the First Meditation he believes that he can draw a conclusion about the impossibility of all objective knowledge. But is he right to do so? Can that meta-knowledge, which may be recognized as a kind of transcendental knowledge, be also deceptive and wrong? Can it not fall under methodic scepticism and sceptical arguments? It is certainly possible. My impressions concerning external things can be wrong in the same way as my knowledge about myself and about my own cognition. And if on the level of the meta-knowledge I find the idea of God which would be a guarantee of the certainty of objective knowledge, this very act can also be doubtful. Perhaps the idea of God and his goodness, which implies the impossibility of deception, is only the result of the evil demon's operations who in this way is trying to deceive me about the value of the clear and distinct cognition.

The conclusion is that after all I could trust myself in the act of objective (empirical) knowledge only if I could trust myself in the act of meta-knowledge (transcendental knowledge) which determines the methodological acceptance criteria of statements which appear at the first level. In other words, I could have a real objective knowledge if I could correctly apply the method, but the method is reliable only when God is not a deceiver and when we were not created by accident. However, in order to know that I was created by a good God, I must already rely on the method applied at the meta-level. But this falls under 
the hypothesis of the evil demon who can mislead me into thinking that I should not be certain about conclusions formulated purely apriorical and analytically. After all it seems that I cannot go beyond myself - I have no authority except me, but my authority is confined to the certainty of my own being - independently of its genesis, nature and purpose. And it is necessary here to add that it is not even self-knowledge, but rather a kind of elementary self-awareness, a primitive intuition accompanying all of my mental acts (and also cognitive mistakes). It is hard to go beyond this intuition and it is hard to get something out of it.

VII.

It may seem that this last issue goes beyond any problems discussed in Zagzebski's book. But it does not. In this example we can see that the problem of the possibility of self-reliance, and of basing it on a selfknowledge, is closely related with the question about my genesis. It is possible to say that the three fundamental questions of Kant - what can I know? what ought I to do? what may I hope? - depend on an answer to this question: where do I come from? And so it seems that the issue of self-reliance is a little bit more complicated than it was presented by Zagzebski and cannot be easily solved by appealing to some of our natural and normal abilities or the common-sense attitude. In my opinion the only way to correctly grasp and formulate this issue is to start from the position of Descartes, or, generally speaking, from the transcendental position, parenthesize our natural attitude, that is everything that common sense and the positive sciences proclaim. I think this is how real philosophy should work. Solving philosophical problems by appealing to common sense is, unfortunately, mixing two diametrically different types of the discourse - philosophical reflection, on the one hand, and our natural attitude on the other. From a philosophical point of view such answers (e.g. common sense solutions to philosophical questions) are trivial, whereas from a common sense perspective they are unnecessary and redundant, because common sense deals with them without any explanations. Kant wrote in Prolegomena: 'To appeal to ordinary common sense when insight and sciences run short, and not before, is one of the subtle discoveries of recent times, whereby the dullest windbag can confidently take on the most profound thinker and 
hold his own with him. So long as a small residue of insight remains, however, one would do well to avoid resorting to this emergency help. ${ }^{5}$ I think that his opinion still prevails.

${ }^{5}$ Immanuel Kant, Prolegomena to Any Future Metaphysics That Will Be Able to Come Forward as Science, trans. G. Hatfield (Cambridge: Cambridge University Press, 2004), p. 259. 